\title{
AVALIAÇÃO DA MATURIDADE DA IMPLEMENTAÇÃO BIM NO CONTEXTO DE ÓRGÃOS PÚBLICOS BRASILEIROS
}

\author{
Vanessa Viana $^{(1)}$, Michele Carvalho ${ }^{(1)}$ \\ (1) Universidade de Brasília, Brasília.
}

\begin{abstract}
Resumo
Building Information Modelling é um processo que altera de forma representativa a indústria AEC (Arquitetura, Engenharia e Construção). As aplicabilidades do BIM atingem todo o ciclo de vida das edificações, trazendo resultados mais eficazes que os métodos tradicionais. Sendo assim, o setor tenta se adaptar buscando sua adoção. Porém, essa deve ser gradual, visto que os processos tradicionais são diferentes dos propostos pelo BIM. Para tal, existem ferramentas que podem auxiliar na condução de sua implantação. Dentre elas, a avaliação da maturidade da implementação, proposta por Bilal Succar em trabalho de título "Building Information Modelling Maturity Matrix”. Esse analisa, através de uma matriz de maturidade, o avanço do processo de adoção da tecnologia em questão. $\mathrm{O}$ presente artigo tem como objetivo avaliar a maturidade da implementação BIM no Departamento Nacional de Infraestrutura em Transportes do Brasil, utilizando-se de tal metodologia. Os resultados mostraram que a metodologia internacional pode ter aplicabilidade e trazer benefícios a esse contexto dos órgãos públicos brasileiros, orientando-os a uma implantação eficiente. As matrizes apresentaram uma maturidade entre a fase baixa e média. Porém, o progresso do órgão tende a evoluir rapidamente, visto que existem ações em fase de desenvolvimento, que tenderão ao avanço da situação atual.
\end{abstract}

\section{Introdução}

A indústria AEC (Arquitetura, Engenharia e Construção) tem passado por profundas mudanças nas últimas décadas, passando de projetos em Computer Aided Design (CAD) para a modelagem 3D. Tal transformação deu-se graças ao Building Information Modeling (BIM), conceituado por [1] como uma abordagem multidisciplinar e baseada em objetos, com o objetivo de facilitar a colaboração entre as partes e a integração de informações relacionadas a objetos ao longo de todo o ciclo de vida de um ativo. O BIM trouxe maior desenvolvimento ao setor da construção, que há muito tempo vem utilizando os mesmos processos, técnicas e materias. Tal, também possibilita a antecipação de cenários, a identificação prévia de erros de projeto e interferências construtivas e maior controle sobre custo e cronograma. Por essa razão é considerado um marco na inovação. 
Naturalmente, prometidos tais ganhos, o mercado tende a iniciar uma migração para o BIM. Países como Dinamarca, Finlândia, Noruega, Singapura, Coreia do Sul e Reino Unido tornaram obrigatório o seu uso em obras públicas, sendo tal obrigação replicada no setor privado por alguns desses. [2] afirma que o entendimento da necessidade do BIM também está se expandindo mundialmente. O Brasil também acompanha tal movimento, principalmente após as ações da Estratégia Nacional de Disseminação do BIM, iniciada em 2018. Como ações dessa, pode-se citar a criação da Plataforma BIM BR. De acordo com [3], a Plataforma, além de possuir conteúdo dinâmico sobre a modelagem da informação da construção, hospedará a biblioteca nacional BIM (BNBIM), cujo intuito é se tornar um repositório das bibliotecas virtuais BIM no Brasil.

Porém decidir por adotar BIM é optar por mudanças profundas nas organizações. Tais mudanças bordam desde questões tecnológicas a questões culturais. Logo, sua adoção deve ser feita com conhecimento de causa. Nesse sentido, [4] afirma que modelos de maturidade tendem a ser úteis, uma vez que oferecem uma estrutura formal capaz de traduzir estratégias em resultados de sucesso consistentes e previsíveis. Existem vários modelos de maturidade consagrados na literatura internacional, principalmente no que se refere ao gerenciamento de projetos. Porém tais não possuem aplicabilidade efetiva no contexto BIM.

A literatura [5] afirma que modelos de maturidade são instrumentos úteis para a difusão do BIM no mundo. Sendo assim, Bilal Succar vem trazer um modelo de maturidade que possa ser aplicado ao processo. Portanto, para medir o desempenho BIM Succar criou uma metodologia que analisa, quantifica e qualifica o uso do BIM em setores, organizações e empreendimentos [6]. Essa foi publicada em 2010 em estudo de título "Building Information Modelling Maturity Matrix - Handbook Of Research On Building Information Modeling And Construction Informatics". O presente artigo tem como objetivo avaliar a maturidade da implementação BIM no Departamento Nacional de Infraestrutura em Transportes do Brasil - DNIT, utilizando-se de tal metodologia proposta por Succar.

\section{Revisão da Literatura}

\subsection{Building Information Modelling (BIM)}

O Building Information Modelling é a nomenclatura do processo que vem alterando mundialmente o cenário da construção civil. O BIM vem ganhando imenso crescimento em suas aplicações na arquitetura, engenharia e construção civil, isso devido às suas capacidades potenciais em eficiência e minimização de erros [7]. O Relatório Nacional de Pesquisa BIM do Reino unido de 2017, afirma que o nível de adoção BIM está em ascensão. Divulga que nesse país a taxa de entrevistados que realmente usam o BIM, aumentou de 13\% em 2011, para 62\% em 2017. Para aumentar os benefícios da colaboração, o setor de AEC está ansioso para avançar além das práticas tradicionais de colaboração que geralmente são baseadas em dados de construção não inteligentes, não interoperáveis e em desenhos 2D [8].

O BIM gera informações precisas e permite aos colaboradores do projeto acessar facilmente informações de vários tipos, promovendo bastante a transparência das informações durante todo o ciclo de vida de um ativo conforme afirma [9]. Também defende que sua utilização resulta em um retorno positivo do investimento em BIM para os colaboradores do projeto, gerando uma economia de 4,8\% dos seus custos. Tal processo não oferece apenas modelos tridimensionais para colaboração entre projetistas e contratados, mas os modelos podem ser 
enriquecidos com outras dimensões para abordar questões de espaço, tempo, segurança, sustentabilidade e outros [10]. Por exemplo, o processo BIM ajudou os profissionais a identificar mais de três milhões e resolver mais de 2,4 milhões de conflitos antes da construção de um grande projeto hospitalar [11].

Embora os benefícios do BIM estejam bem estabelecidos, os participantes do projeto ainda enfrentam desafios significativos que interrompem e dificultam o processo de coordenação, mesmo quando as ferramentas do BIM estão prontamente disponíveis [12]. Por esse motivo, a decisão de implementa-lo em uma organização é desafiadora, visto que essa necessita avaliar os benefícios, custos e desafios. A adoção BIM requer planejamento, monitoramento contínuo e execução. Tais ações tomadas permitiria o progresso da avaliação comparativa, desenvolvendo soluções e aplicação de intervenções que possam ajudar o setor a alcançar substanciais benefícios, principalmente através da colaboração [8]. Tal acompanhamento pode ser realizado via modelos de maturidade.

\subsection{Modelos de Maturidade}

No que diz respeito às organizações, [13] afirma que modelos de maturidade reconhecem e sinalizam seu amadurecimento progressivo. Assim, instituições podem se apoiar em modelos de maturidade para acompanhar a evolução de implementações, mudanças ou seu desenvolvimento de uma forma geral; entendendo assim seu progresso de forma clara. Tornando-se possível até mesmo prever seu futuro desempenho dentro de determinada área ou conjunto de disciplinas [14], pontos fracos e aspectos bem-sucedidos

Modelos de maturidade podem ser aplicados em diversas áreas de organizações, sendo gerenciamento de projetos, uma das mais representativas. Nesse contexto, [15] define um modelo de maturidade como o mecanismo capaz de quantificar numericamente a capacidade de uma organização gerenciar projetos com sucesso. De acordo com [16], entre os modelos de maturidade de gestão de projetos mais difundidos estão: OPM3 - Organizational Project Management Maturity Model e o CMM - Capability Maturity Model.

O OPM3 - Organizational Project Management Maturity Model é um modelo para avaliação da maturidade organizacional em gestão de projetos, proposto pelo Project Management Institute $\left(\mathrm{PMI}{ }^{\circledR}\right)$. O objetivo do OPM3 é permitir às empresas a visualização das capacidades necessárias, para que possam implementar suas estratégias com consistência e previsibilidade [17]. No que se trata do CMM, [18] trazem que o modelo de maturidade foi proposto pelo Software Engineering Institute da Carnegie Mellon University. Sua estrutura se apresenta em níveis de capacidade, seguindo uma ordem recomendada para abordar a melhoria do processo dentro de cada área de processo especificada [19].

\subsubsection{Maturidade BIM}

No contexto BIM, [20] trazem o termo "maturidade" denotando a extensão da capacidade na execução de uma tarefa ou na entrega de um serviço/produto BIM. Ou seja, maturidade do BIM refere-se à qualidade, repetitividade e grau de excelência dentro de uma capacidade BIM. Pesquisadores da área em discussão [1] afirmam que a avaliação da maturidade na implementação do BIM em organizações, identifica o status atual de implementação de empresas individualmente e dos subsetores relacionados.

Níveis inconsistentes de maturidade do BIM entre as partes colaboradoras em um projeto limitam o grau em que as metas do BIM e as expectativas de acompanhamento podem ser 
realizadas, especialmente em relação aos usos do BIM com ampla troca de dados entre as partes $[21,1]$.

Quando os requisitos de cada nível são satisfeitos, os implementadores podem, então, construir componentes estabelecidos para tentar uma maturidade "mais alta" [20]. Sendo assim, modelos de maturidade também podem ser considerados guias. Baseado nos níveis de maturidade apresentados, dirigentes sabem quais as próximas medidas devem ser tomadas e priorizadas.

O conceito de maturidade BIM foi adotado a partir do Capability Maturity Model (CMM), do Software Engineering Institute's [22]. Autores [23] afirmam que indústria de software CMM original não é aplicável ao setor de construção; visto que não aborda questões da cadeia de suprimentos. Os níveis de maturidade CMM também não levam em conta as diferentes fases do ciclo de vida de um projeto de construção [23]. Embora outros esforços, derivados do CMM, enfoquem o setor de construção, não há modelo/índice de maturidade abrangente que possa ser aplicado ao BIM, seus estágios de implementação, entregáveis ou seu efeito nas fases do ciclo de vida do projeto [20].

Nesse contexto, foi então desenvolvida por Bilal Succar, uma metodologia para lidar com a mudança de cultura proporcionada pelo BIM, publicada em $2010 \mathrm{com}$ nome já citado no texto. Para [24], os indicadores gerados por esse procedimento, torna possível a equipes e organizações medir conscientemente seus ganhos e perdas, avaliar suas próprias competências BIM e comparar-se em relação aos parâmetros da indústria. Pesquisadores [25] esclarecem que a existência de um meio que permita organizar a avaliação, aquisição e aplicação de competências BIM também facilita sua adoção e esclarece as atividades complexas para a realização da colaboração multidisciplinar.

Os níveis de maturidade em BIM são definidos por [6] como a representação da qualidade, previsibilidade e variabilidade dentro dos Estágios do BIM, sendo esses: modelagem, colaboração e integração. O conceito de maturidade em BIM pode ser mensurado em um índice: o BIM Maturity Index (BIMMI), para a maturidade da implementação como um todo; e também pode ser atribuído individualmente às diferentes áreas de capacidade BIM (12 áreas). Tais níveis são: inicial, definido, gerenciado, integrado e otimizado [24]. Tais níveis estão discriminados para cada uma das doze áreas de capacidade BIM, no Anexo A.

Tal índice é gerado através da matriz de maturidade BIM $\left(\mathrm{BIm}^{3}\right)$ pode ser utilizada por diferentes agentes da AEC, de diferentes escalas organizacionais e em diferentes pontos do ciclo devida de um projeto.

A BIm $^{3}$ tem dois eixos: Conjuntos de Capacidade em BIM, Estágios BIM e Escalas Organizacionais, no eixo das ordenadas e Índice de Maturidade, no eixo das abscissas. As tabelas que guiam a avaliação dos requisitos estão divididas em cinco partes: tecnologia, processos, políticas, estágios e escala, como mostra o Anexo A. Vale ressaltar, que inicialmente o estágio de capacidade em que a entidade se encontra e a escala organizacional são inicialmente definidos, para então ser atribuída sua maturidade.

Relacionado os conjuntos de capacidade em BIM, estágios BIM e escalas Organizacionais, com seu respectivo nível maturidade, gera-se a $\mathrm{BIm}^{3}$. Passa-se então para a etapa de transformar tais aspectos em dados quantitativos. Com base nos dados disponibilizados pela matriz de maturidade, Bilal Succar [24] desenvolveu o Grau de Maturidade e o Índice de Maturidade.

Para cada área de competência, considerando a escala organizacional e o estágio de capacidade, pontua- se conforme o nível de maturidade. A escala de pontuação é progressiva e acumulativa, logo, só se pode passar a um nível de maturidade mais alto tendo como pressuposto o cumprimento total do nível de maturidade anterior. A escala de pontuação é de 10, 20, 30, 40 
e 50 pontos, respectivamente, para os níveis de maturidade inicial, definido, gerenciado, integrado e otimizado. Totalizada a pontuação, calcula-se o grau de maturidade e o índice de maturidade.

O Grau de Maturidade é a média aritmética da pontuação em todas as áreas. Como são 12 áreas, o valor é calculado somando-se as pontuações individuais das áreas e dividindo-se o resultado por 12. Já o Índice de Maturidade é o que o valor obtido neste primeiro cálculo representado percentualmente em relação ao valor de 50, que corresponde à pontuação máxima que se pode ter em cada uma das áreas. Esse percentual resultante indica uma posição em um quadro classificatório de Nível de Maturidade em BIM, referente ao nível global em que se classifica a organização.

\section{Metodologia}

\subsection{Avaliação da Maturidade dos Órgãos Públicos}

A metodologia a seguir, consiste em identificar o status atual de implementação BIM do órgão sob análise. Inicialmente, entrou-se em contato com o órgão e identificou-se um programa em processo de adoção BIM. Esse programa chama-se Programa de Manutenção e Reabilitação de Estruturas - PROARTE, e tem como objetivo principal o gerenciamento de serviços de manutenção e de reabilitação em obras de arte especiais - pontes, túneis, viadutos, passarelas e estruturas de contenção - em toda a malha rodoviária federal do país. Nesse, a utilização do BIM estaria focada nos serviços de reabilitação, que englobam o reforço das obras de arte e/ou alargamento das mesmas, mais especificamente na fase de criação de pré-projetos. Após a apresentação da equipe do PROARTE, foram realizados encontros onde a metodologia de trabalho e demais aspectos relevantes à pesquisa foram descritos e apresentados. Sendo assim, buscou-se reuniões com membros de diversos setores do programa e com membros da diretoria a qual tal é subordinado. Essa abordagem proporcionou o entendimento integral dos aspectos referentes ao PROARTE. Por fim, a metodologia de Succar foi aplicada a um membro do programam em questão, identificado como representativo e a um membro da diretoria executiva do órgão, a qual o projeto é subordinado. Dessa forma, após o envio da $\mathrm{BIm}^{3}$ via e-mail aos interessados e retorno, obteve-se dois resultados de maturidade do BIM no órgão.

A primeira foi gerada baseada nas percepções do integrante do programa, que lida com a execução dos pré-projetos em si, ou seja, questões relacionadas ao nível operacional do BIM. A segunda foi baseada nas percepções do integrante da diretoria executiva, que lida com questões a nível tático relacionadas com, por exemplo, processos de projeto e de trabalho órgão. Vale relembrar que esse método entrega quatro principais produtos: a matriz de maturidade BIM $\left(\mathrm{BIm}^{3}\right)$, o grau de maturidade em BIM, o índice de maturidade em BIM e o nível de maturidade global em BIM. Sendo assim, foram obtidos dois pacotes de resultados: um a nível operacional e outro a nível tático.

\subsubsection{Matriz de Maturidade BIM (BIm $\left.{ }^{3}\right)$}

A BIm ${ }^{3}$ possui dois eixos: conjuntos de capacidade em BIM, estágio de capacidade e escala organizacional (ordenadas); e índice de maturidade (abscissas). O conjunto de capacidades em BIM se traduzem nas competências em BIM. Essas competências se dividem da seguinte maneira: 
- Tecnologia: software; hardware; e rede;

- Processos: recursos; atividades e fluxo de trabalho; produtos e serviços; e liderança e gerenciamento;

- Política: preparatória; regulatória; e contratual.

O estágio de capacidade se refere ao estágio de implementação atingido pela organização e escala organizacional se refere às variações de escala de empresa, sendo classificadas em: micro, meso e macro. A maturidade BIM se refere às melhorias graduais e contínuas em qualidade, repetitividade e previsibilidade dentro da capacidade BIM disponível. É medida através de cinco níveis: inicial, definido, gerenciado, integrado e otimizado.

Antes do desenvolvimento da matriz foram definidos o estágio de capacidade em que o órgão se encontra e a escala organizacional. A $\mathrm{BIm}^{3}$ foi construída atribuindo-se ao estágio, escala organizacional e a cada subitem do conjunto de capacidades um nível de maturidade. Essas atribuições foram feitas tendo como base as informações disponibilizadas pelos responsáveis pela implementação BIM no órgão. Essas atribuições ainda foram fundamentadas nas definições para cada de nível de maturidade propostas por Succar (2010a) e nas definições presentes no Anexo A: Matriz de Maturidade BIM (BIm³).

\subsubsection{Grau e Índice de Maturidade em BIM}

Tendo os níveis de maturidade para cada área de competência, pontuou-se em 10, 20, 30, 40 e 50 pontos, respectivamente, para os níveis de maturidade inicial, definido, gerenciado, integrado e otimizado. Obteve-se o grau de maturidade com a média aritmética da pontuação de todas as áreas (estágio; escala; e três subdivisões de tecnologia, quatro subdivisões de processos e três subdivisões de políticas). Considerando 12 áreas, o valor foi calculado somando-se as pontuações individuais de cada área e dividindo-se o resultado por 12. Chegouse ao índice de maturidade calculando-se o valor representado pela porcentagem do valor do grau de maturidade em relação a 50, que corresponde à pontuação máxima que se pode ter em cada uma das áreas.

\subsubsection{Nivel de Maturidade Global em BIM}

Tendo o percentual indicado pelo índice de maturidade, obteve-se o nível de maturidade da implementação da empresa como um todo. Esse percentual resultante indica uma posição em um quadro classificatório, apresentado no Quadro 1, definindo a empresa em: baixa, médiabaixa, média, média-alta e alta maturidade.

Quadro 1: Quadro classificatório de nível de maturidade referente ao nível global em que se classifica a organização. Fonte: [25]

\begin{tabular}{lccc}
\hline Nível & Nome do nível & Classificação textual & Classificação numérica \\
\hline A & Inicial & Baixa maturidade & $0-19 \%$ \\
B & Definido & Média-baixa maturidade & $10-39 \%$ \\
C & Gerenciado & Média maturidade & $40-59 \%$ \\
D & Integrado & Média-alta maturidade & $60-79 \%$ \\
E & Otimizado & Alta maturidade & $80-100 \%$ \\
\hline
\end{tabular}




\section{Resultados e Análises}

Obtidas as informações via e-mail dos dois integrantes do órgão, foram feitas as análises com objetivo de se chegar à maturidade da implementação BIM a nível tático e operacional. Na Tabela 1 e Tabela 2 seguem as informações adquiridas. Observa-se na Tabela 1, a classificação do nível de maturidade para o conjunto de capacidades em BIM a níveis operacionais, resultando em um nível de maturidade $\mathrm{C}$ - gerenciado, que corresponde a uma média maturidade. Já na Tabela 2, tal classificação do conjunto de capacidades em BIM resultou para o nível tático uma maturidade nível $\mathrm{B}$ - definido, que corresponde a uma média-baixa maturidade.

Para [24] o nível de maturidade "gerenciado", atribuído ao PROARTE é definido como: Empresas ou organizações que têm objetivos claros, com planos de ação e monitoramento. Além disso, a visão do BIM é compartilhada entre todos os funcionários. São institucionalizadas as metas do BIM, que passam a ser alcançadas de forma mais ou menos regular. São reconhecidas as mudanças nas esferas da tecnologia, processos e políticas. As especificações dos produtos e os padrões de entrega seguem normas nacionais ou internacionais. Existe o gerenciamento da modelagem e dos dados do modelo, com padrões detalhados e planos de qualidade. A colaboração entre parceiros prevê alocação de risco e atribuição de responsabilidades, mas, também as recompensas, podendo existir parcerias a longo prazo.

Tal descrição corrobora com o que foi vivenciado ao longo do tempo de desenvolvimento da pesquisa, em que se teve contato com o programa PROARTE aqui em estudo. Contato esse, que se estendeu por dois meses, onde foram realizadas reuniões com os colaboradores submetidos ao estudo e trocas de e-mails com o intuído de se obter os dados aqui em análise No PROARTE, os funcionários possuíam ou estavam passando por capacitação BIM, os dirigentes estavam bem alinhados com metas que tinham que atingir, havia respeito a normas e protocolos BIM já existentes e demais estratégias e medidas sugeridas por planos de implementação eram respeitadas. Tal cenário favorável pode ser explicado devido à natureza desse programa: desenvolve um dos primeiros projetos pilotos identificados pela estratégia BIM BR. Sendo assim, os processos tendem a estarem sendo desenvolvidos de maneira séria e acompanhada. Identifica-se que a nível operacional, o desenvolvimento da implementação BIM esteja gerando bons resultados no órgão e com tendência a evolução, uma vez que os processos estão sendo seguidos de acordo com o que, por exemplo, a coletânea de guias de adoção da Agência Brasileira de Desenvolvimento Industrial - ABDI, em parceria com o Ministério da Indústria, Comércio Exterior e Serviços - MDIC [26]; descrevem.

Bilal Succar [24] define o nível de maturidade "definido", atribuído à diretoria executiva como: os gerentes seniores orientam o uso do BIM. Já existe a documentação de processos e políticas. Existem diretrizes para o BIM, manuais de treinamento, guias de trabalho e padrões de entrega. O BIM é visto como inovação e oportunidade de negócio, mas as possibilidades do mercado ainda não são exploradas. A competência geral aumenta, diminuindo a ideia de "esforço heroico", contudo, ainda não é possível prever a produtividade da equipe. Existe confiança entre parceiros de projeto e a colaboração segue guias de processo, padrões e protocolos de intercâmbio pré-definidos. Os contratos preveem alocação de risco e atribuição de responsabilidades. 
Tabela 1: Matriz de maturidade BIM $\left(\mathrm{BIm}^{3}\right)$ - Preenchida. Nível operacional

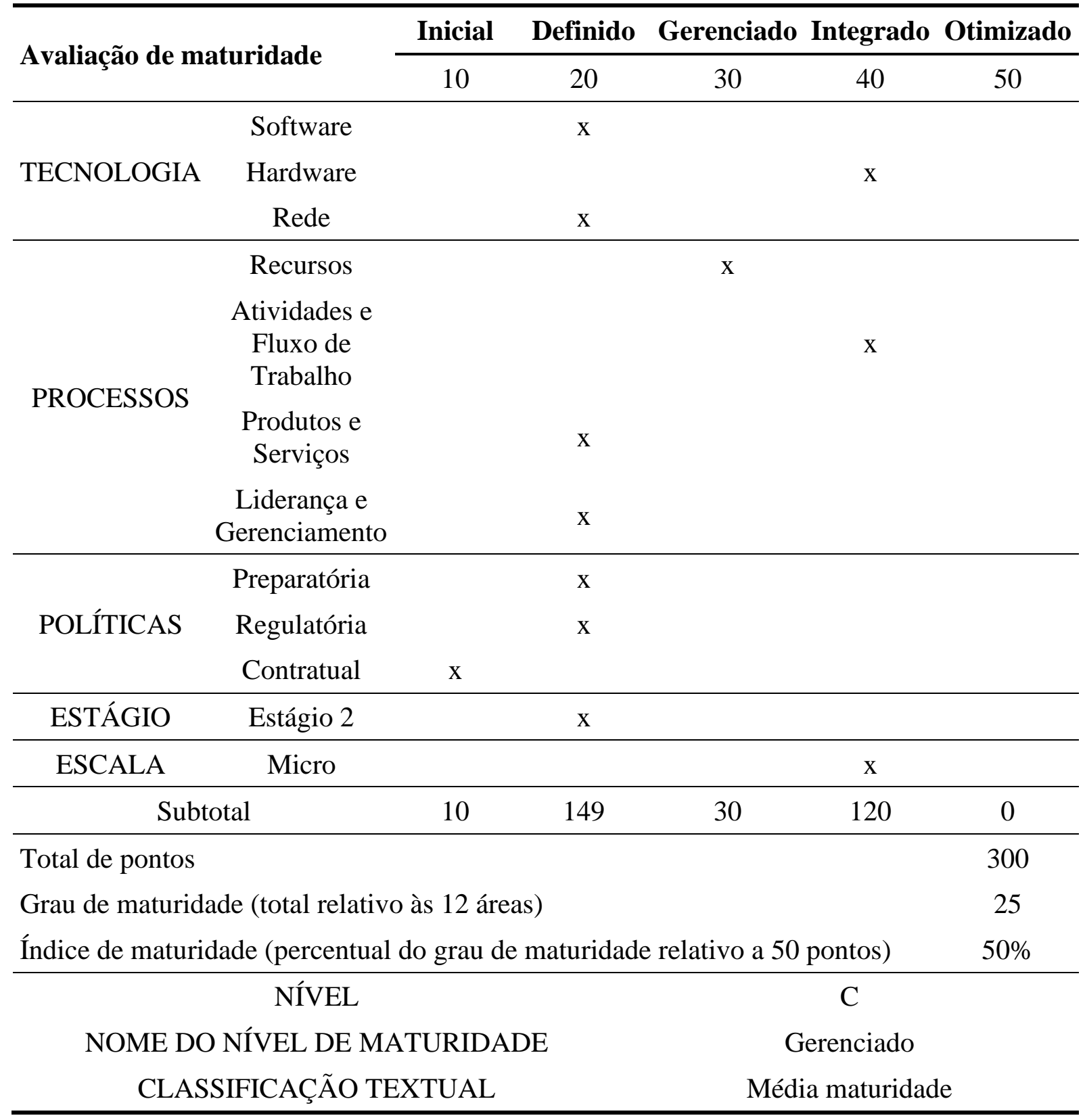

Tal descrição corresponde com o apresentado na diretoria. Como o grupo é formado por um número pequeno de pessoas (três), ainda existe o acúmulo de tarefas e funções; porém há a tentativa de colaboração entre as partes. Vale ainda ressaltar que tais personagens possuem bastante bagagem na temática. Existe uma grande quantidade de documentos produzidos e compilados, visando nortear o desenvolvimento do BIM no órgão a nível tático e segue-se as orientações do plano de adoção BIM. Buscando assim a evolução no setor.

A disparidade apresentada entre as duas análises, podem ser atribuída ao tempo de elaboração das mesmas. As operações a nível tático começam a ser desenvolvidas após o início das atividades da estratégia nacional. Sendo assim, as atividades desempenhadas pelos envolvidos 
precisaram de um tempo para ser desenvolvidas e adequadas à realidade do setor. $\mathrm{O}$ mesmo aconteceu a nível operacional, porém com menor impacto. As atividades também precisaram ser criadas. Porém os envolvidos já possuíam certa capacidade, como por exemplo, utilizar as ferramentas de maquete, parte integrante do processo BIM que tem bastante enfoque no nível operacional. O que pode ter dado certa vantagem e maior rapidez ao desenvolvimento da implementação BIM no programa.

Tabela 2: Matriz de maturidade BIM (BIm³)-Preenchida. Nível tático

\begin{tabular}{|c|c|c|c|c|c|c|}
\hline \multirow{2}{*}{\multicolumn{2}{|c|}{ Avaliação de maturidade }} & Inicial & Definido & Gerenciado & Integrado & Otimizado \\
\hline & & 10 & 20 & 30 & 40 & 50 \\
\hline \multirow{3}{*}{ TECNOLOGIA } & Software & $\mathrm{x}$ & & & & \\
\hline & Hardware & & $\mathrm{x}$ & & & \\
\hline & Rede & $\mathrm{x}$ & & & & \\
\hline \multirow{4}{*}{ PROCESSOS } & Recursos & $\mathrm{x}$ & & & & \\
\hline & $\begin{array}{c}\text { Atividades e } \\
\text { Fluxo de } \\
\text { Trabalho }\end{array}$ & $\mathrm{x}$ & & & & \\
\hline & $\begin{array}{l}\text { Produtos e } \\
\text { Serviços }\end{array}$ & $\mathrm{x}$ & & & & \\
\hline & $\begin{array}{c}\text { Liderança e } \\
\text { Gerenciamento }\end{array}$ & $\mathrm{x}$ & & & & \\
\hline \multirow{3}{*}{ POLÍTICAS } & Preparatória & & $\mathrm{x}$ & & & \\
\hline & Regulatória & $\mathrm{x}$ & & & & \\
\hline & Contratual & $\mathrm{x}$ & & & & \\
\hline ESTÁGIO & Estágio 1 & $\mathrm{x}$ & & & & \\
\hline ESCALA & Meso & $\mathrm{x}$ & & & & \\
\hline \multicolumn{2}{|c|}{ Subtotal } & 100 & 40 & 0 & 0 & 0 \\
\hline \multicolumn{6}{|l|}{ Total de pontos } & 140 \\
\hline \multicolumn{6}{|c|}{ Grau de maturidade (total relativo às 12 áreas) } & 11,67 \\
\hline \multicolumn{6}{|c|}{ Índice de maturidade (percentual do grau de maturidade relativo a 50 pontos) } & $23 \%$ \\
\hline \multicolumn{4}{|c|}{ NÍVEL } & \multicolumn{3}{|c|}{ B } \\
\hline \multicolumn{4}{|c|}{ NOME DO NÍVEL DE MATURIDADE } & \multicolumn{3}{|c|}{ Definido } \\
\hline \multicolumn{4}{|c|}{ CLASSIFICAÇÃO TEXTUAL } & \multicolumn{3}{|c|}{ Média-baixa maturidade } \\
\hline
\end{tabular}




\section{Conclusão}

Os objetivos principais desse estudo se referiam à avaliação da maturidade da implementação BIM no Departamento Nacional de Infraestrutura em Transportes do Brasil - DNIT, utilizandose de tal metodologia proposta por Succar; sendo esse atingido com sucesso. Tal metodologia proposta visava por meio do preenchimento da matriz de maturidade BIM - BIm ${ }^{3}$ chegar-se ao grau e ao índice de maturidade da implementação do órgão em estudo. Posteriormente o índice seria aplicado a um quadro classificatório que geraria o nível de maturidade da adoção BIM. No presente estudo, a $\mathrm{BIm}^{3}$ foi aplicada a nível operacional e tático do órgão em análise, gerando resultados díspares. Para o programa PROARTE, a maturidade foi classificada como média-alta, com um nível de maturidade "gerenciado". O que corroborou com as percepções vivenciadas durante a coleta de dados. Já a diretoria executiva do órgão, no qual o PROARTE está subordinado, teve uma classificação média, com nível de maturidade "definido". Tal resultado também condiz com o cenário percebido durante avaliação.

A explicação para tal defasagem da diretoria pode estar relacionada ao tempo desenvolvimento das atividades correspondentes a implementação em cada setor. Como os procedimentos a nível operacional envolvem mais fortemente o uso das tecnologias como ferramentas de trabalho, mais claramente o uso dos softwares BIM, a existência de funcionários já capacitados quando do início do processo, pode ter levado a criação de uma vantagem ao desenvolvimento da adoção no setor. Já a nível tático, as ações envolvem processos de projeto e de trabalho, que precisam ser desenvolvidas do zero ou compiladas a partir de normas e protocolos BIM existentes. Necessitando assim de mais tempo ao amadurecimento das atividades e procedimentos. Trabalhos como esse, mostram como o modelo de maturidade internacional trazem benefícios mesmo em um contexto específico, como o dos órgãos públicos brasileiros, orientando-os a uma implantação BIM mais eficiente. Tal situação assim, pode ser replicada a outros contextos e/ou outros países com ganhos também significativos, no que tangem a identificação da fase atual de desenvolvimento da implementação BIM.

\section{Referências}

[1] S. SIEBELINK; J. T. VOORDIJK; A. ADRIAANSE, "Developing and Testing a Tool to Evaluate BIM Maturity: Sectoral Analysis in the Dutch Construction Industry" in Journal Of Construction Engineering And Management (2018), American Society of Civil Engineers (ASCE), 2018, pp 45-59. doi: 10.1061/(asce)co.1943-7862.0001527.

[2] A. GHAFFARIANHOSEINI; et al., "Building Information Modelling (BIM) uptake: Clear benefits, understanding its implementation, risks and challenges" in Renewable And Sustainable Energy Reviews (2017), Elsevier BV, 2017, pp 1046-1053. doi: 10.1016/j.rser.2016.11.083.

[3] ABDI, Agência Brasileira de Desenvolvimento Industrial. A BNBIM. Disponível em: https://plataformabimbr.abdi.com.br/bimBr/\#/conteudo/62. Acesso em: 10 jun. 2020.

[4] M. M. SOELTL, "Análise da maturidade em gerenciamento de projetos e seu impacto nos projetos de desenvolvimento de novos produtos: um estudo de caso do setor automotivo", Dissertação de Mestrado, Universidade de São Paulo, Curso de Engenharia Automotiva, Escola Politécnica, São Paulo, Brasil, 2006. 
[5] C. Liang, et al., "Development of a Multifunctional BIM Maturity Model" in Journal Of Construction Engineering And Management (2016), American Society of Civil Engineers (ASCE), 2016, pp 157-166. doi:10.1061/(asce)co.1943-7862.0001186.

[6] W. R. dos Santos, "Estudos de Caso de Implementação da Modelagem da Informação da Construção em Microescritórios de Arquitetura: Estudos de Caso de Implementação da Modelagem da Informação da Construção em Microescritórios de Arquitetura", Dissertação de Mestrado, Instituto de Pesquisas Tecnológicas do Estado de São Paulo IPT, Curso de Planejamento, Gestão e Projeto, São Paulo, Brasil, 2016.

[7] C. M. Eastman, P. Teicholz, R. Sacks, and K. Liston, BIM handbook : a guide to Building Information Modeling for owners, managers, designers, engineers, and contractors. Hoboken, N.J.: Wiley, 2011.

[8] C. Vidalakis; F. H. Abanda; A. H. Oti, "BIM adoption and implementation: focusing on SMEs", in Construction Innovation (2020), Emerald, 2020, p.128-147. doi: 10.1108/ci-092018-0076.

[9] U. Haider et al., "Cost Comparison of a Building Project by Manual and BIM", in Civil Engineering Journal (2020), Ital Publication, 2020, pp. 34-49. doi:10.28991/cej-202003091451.

[10]D. Liu; Z. Jin; J. Gambatese. "Scenarios for Integrating IPS-IMU System with BIM Technology" in Construction Safety Control. Practice Periodical On Structural Design And Construction (2020), American Society of Civil Engineers (ASCE), 2020, pp.51-69. doi:10.1061/(asce)sc.1943-5576.0000465.

[11]A. Khanzode; "An Integrated, Virtual Design and Construction and Lean (IVL) Method for Coordination of MEP", in Center For Integrated Facility Engineering-CIFE (2010), Stanford University, 2010, pp.187-199.

[12] S. Mehrbod; S. Staub-French; Y. Bai, "Analysis Of Bottlenecks In Bim-Based Building Design Coordination Process And Benchmarking State Of The Art Bim Tools" in Canadian Society for Civil Enginenering (2017), Vancouver, Canada, 2017, pp. 1-10.

[13]H. R. de Almeida Neto, "Um Modelo de Maturidade para Governança Ágil em Tecnologia da Informação e Comunicação", Tese de Doutorado, Universidade Federal de Pernambuco, Programa de Pós-graduação em Ciência da Computação, Centro de Informática, Pernambuco, Brasil, 2015.

[14] SEI - Software Engineering Institute, The Capability Maturity Model: guidelines for improving the software process, MA: Addison-Wesley, 1995.

[15]D. Prado, Maturidade em Gerenciamento de Projetos, 3 ed., Falconi, Nova Lima, 2015

[16] J. C. A. da Silva Neto, "Avaliação De Maturidade No Gerenciamento De Projetos Em Uma Empresa De Mineração Em Minas Gerais", Dissertação de Mestrado, Universidade FUMEC - Fundação Mineira de Educação e Cultura, Curso de Mestrado em Administração, Faculdade de Ciências Empresariais, Belo Horizonte, Brasil, 2011.

[17] PMI - Project Management Institute, Organizational Project Management Maturity Model (OPM3®): Knowledge Foundation, 3 ed., PMI, USA, 2013.

[18]M. Rosemann; T. Bruin, "Towards a Business Process Managment Maturity Model", in European Conference On Information Systems (ECIS) (2005), AIS Electronic Library (AISeL), 2005, pp 100-113.

[19] CMMI Product Team for Development, Improving processs for developing better products and services, CMU/SEI-2010-TR-033, Software Engineering Institute, 2010. 
[20]B. Succar; W. Sher; A. Williams, "Measuring BIM performance: Five metrics" in . Architectural Engineering And Design Management (2012), UK, 2012, pp.120-142. doi: 10.1080/17452007.2012.659506.

[21]A. Adriaanse; H. Voordijk; G. Dewulf, "Adoption and Use of Interorganizational ICT in a Construction Project" in Journal Of Construction Engineering And Management (2010), American Society of Civil Engineers (ASCE), 2010, pp 1003-1024. doi: 10.1061/(asce)co.1943-7862.0000201

[22] SEI - Software Engineering Institute, The Capability Maturity Model: guidelines for improving the software process, MA: Addison-Wesley, 2008.

[23] M. Sarshar; et al., "A Business Process Diagnostics Tool For Construction Projects. Engineering", in Construction And Architectural Management (2000), Emerald, 2000, pp 241-250. doi: 10.1108/eb021149.

[24]B. Succar, "Building Information Modelling Maturity Matrix. Handbook Of Research On Building Information", in Modeling And Construction Informatics (2010), IGI Global, 2010, pp 65-103. doi: 10.4018/978-1-60566-928-1.ch004.

[25] B. Succar; W. Sher; A. Williams, "An integrated approach to BIM competency assessment, acquisition and application" in . Automation In Construction (2013), Elsevier BV, 2013, pp 174-189. doi:10.1016/j.autcon.2013.05.016.

[26]ABDI, Agência Brasileira de Desenvolvimento Industrial. Coletânea Guias BIM ABDIMDIC. Brasília, DF: ABDI, 2017. 
ptBIM $2020-3^{\circ}$ Congresso Português de Building Information Modelling

26 e 27 de novembro e 4 de dezembro de 2020, Faculdade de Engenharia da Universidade do Porto

Anexo A - Matriz de Maturidade BIM (BIm). Fonte: [24]

\begin{tabular}{|c|c|c|c|}
\hline (1) & 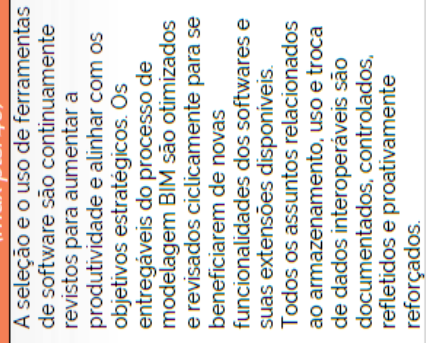 & 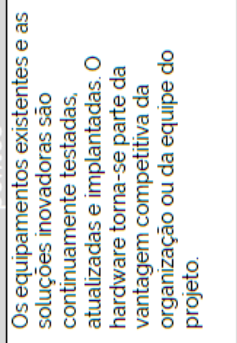 & 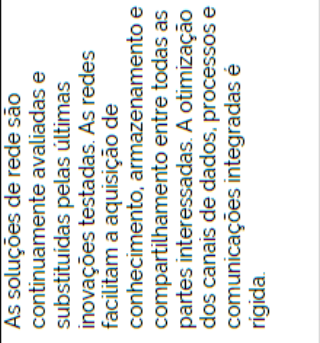 \\
\hline & 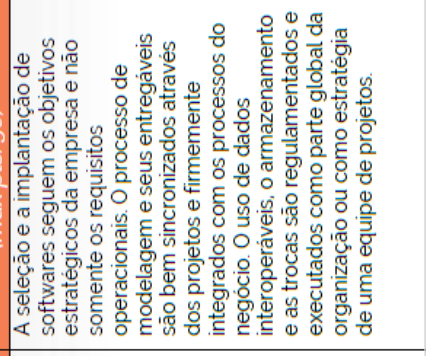 & 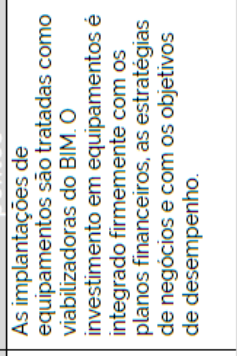 & 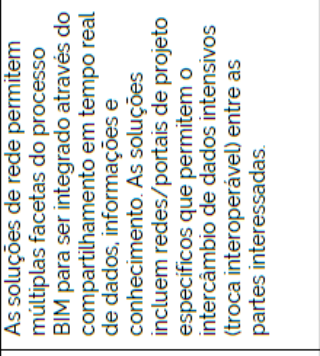 \\
\hline ن & 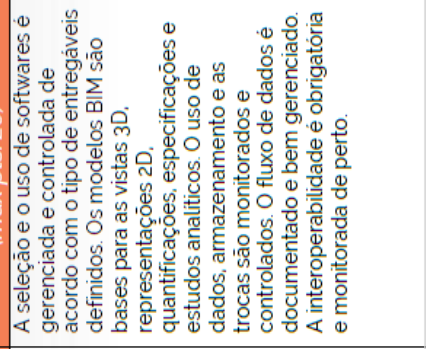 & 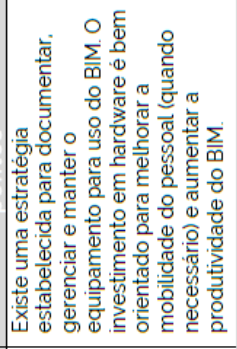 & 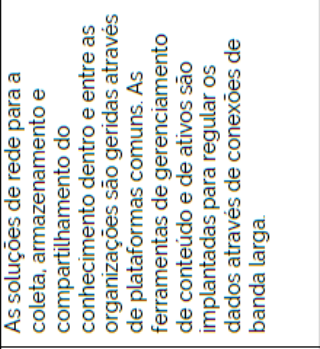 \\
\hline ㅇ. & 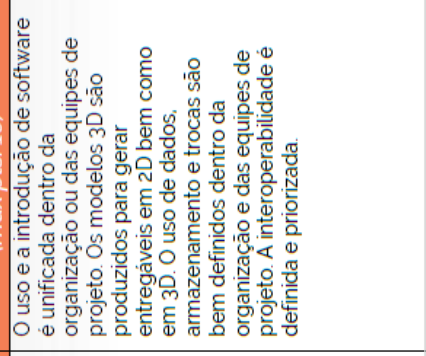 & 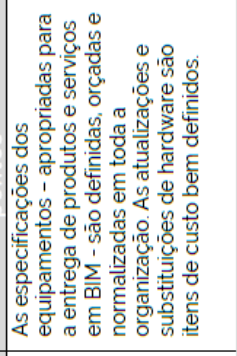 & 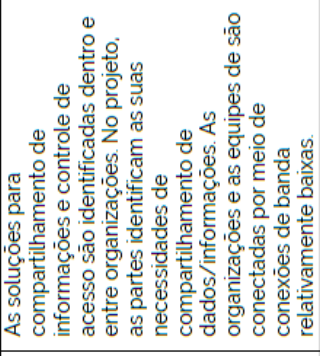 \\
\hline त) $\frac{\frac{\pi}{U}}{\underline{Z}}$ & 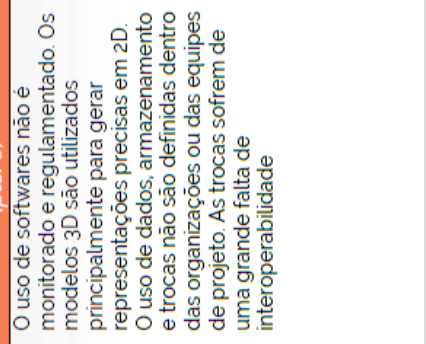 & 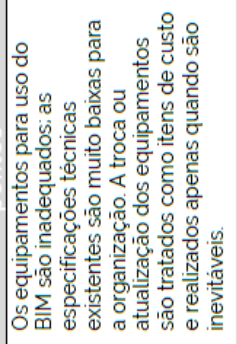 & 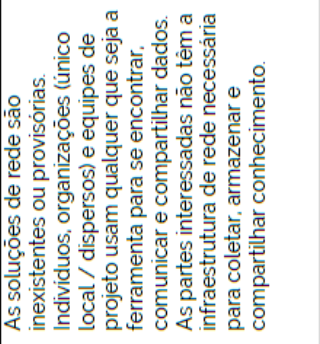 \\
\hline 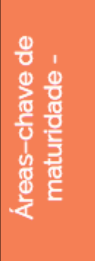 & 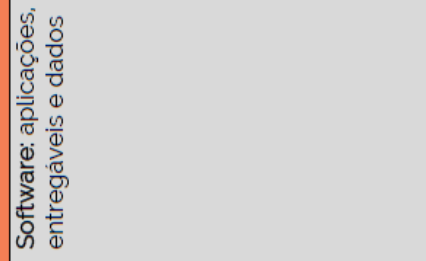 & 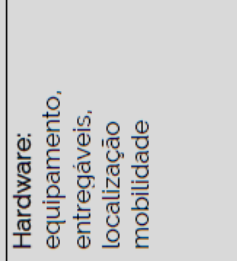 & 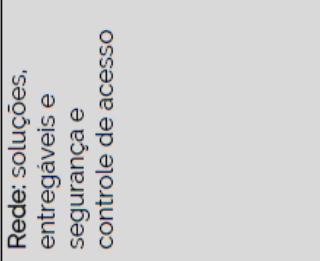 \\
\hline & \multicolumn{3}{|c|}{ 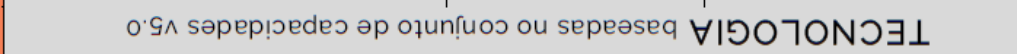 } \\
\hline
\end{tabular}

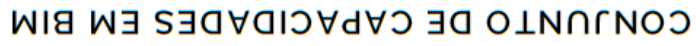


ptBIM $2020-3^{\circ}$ Congresso Português de Building Information Modelling

26 e 27 de novembro e 4 de dezembro de 2020, Faculdade de Engenharia da Universidade do Porto

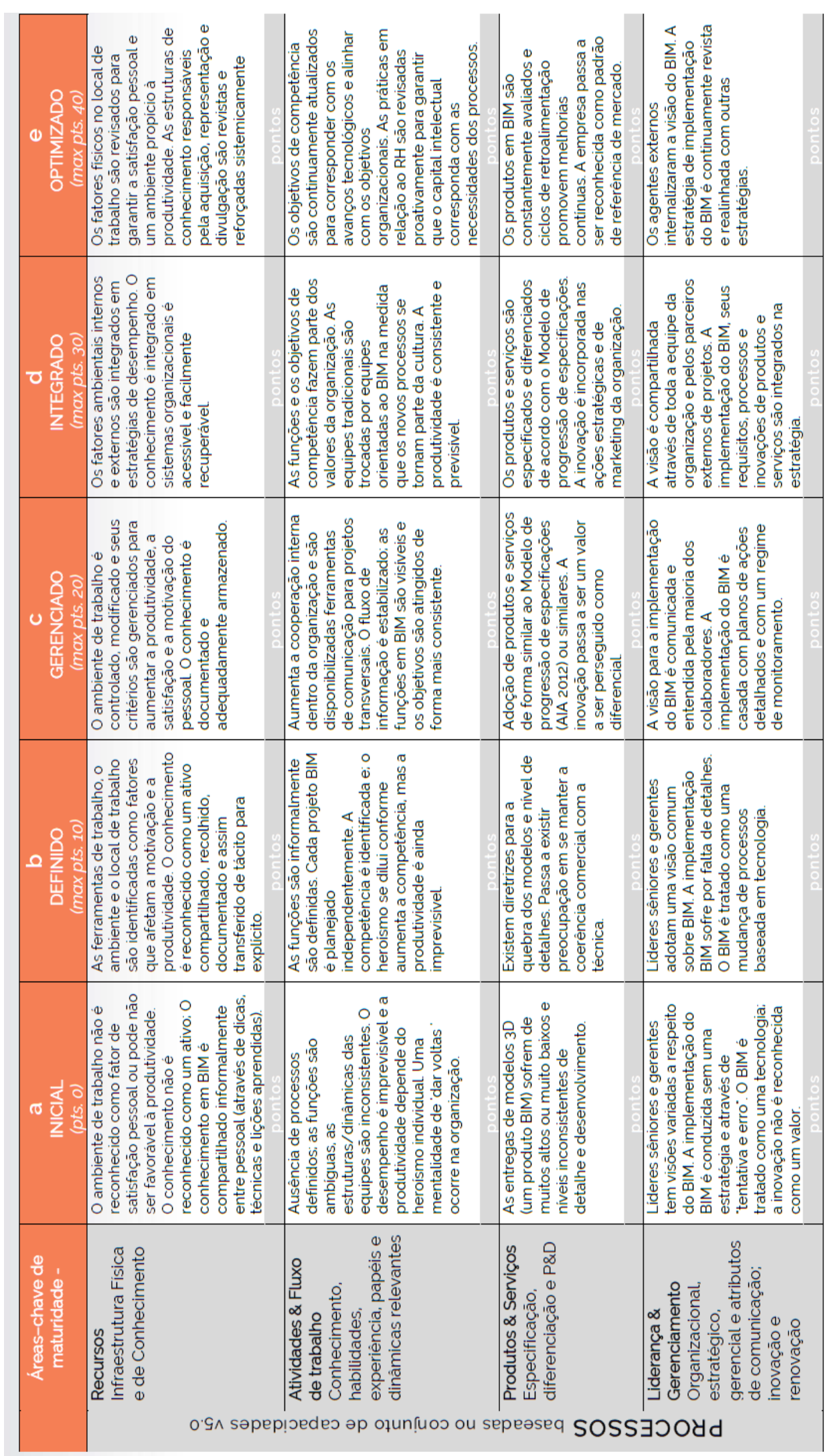

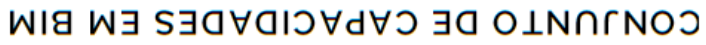


ptBIM $2020-3^{\circ}$ Congresso Português de Building Information Modelling

26 e 27 de novembro e 4 de dezembro de 2020, Faculdade de Engenharia da Universidade do Porto

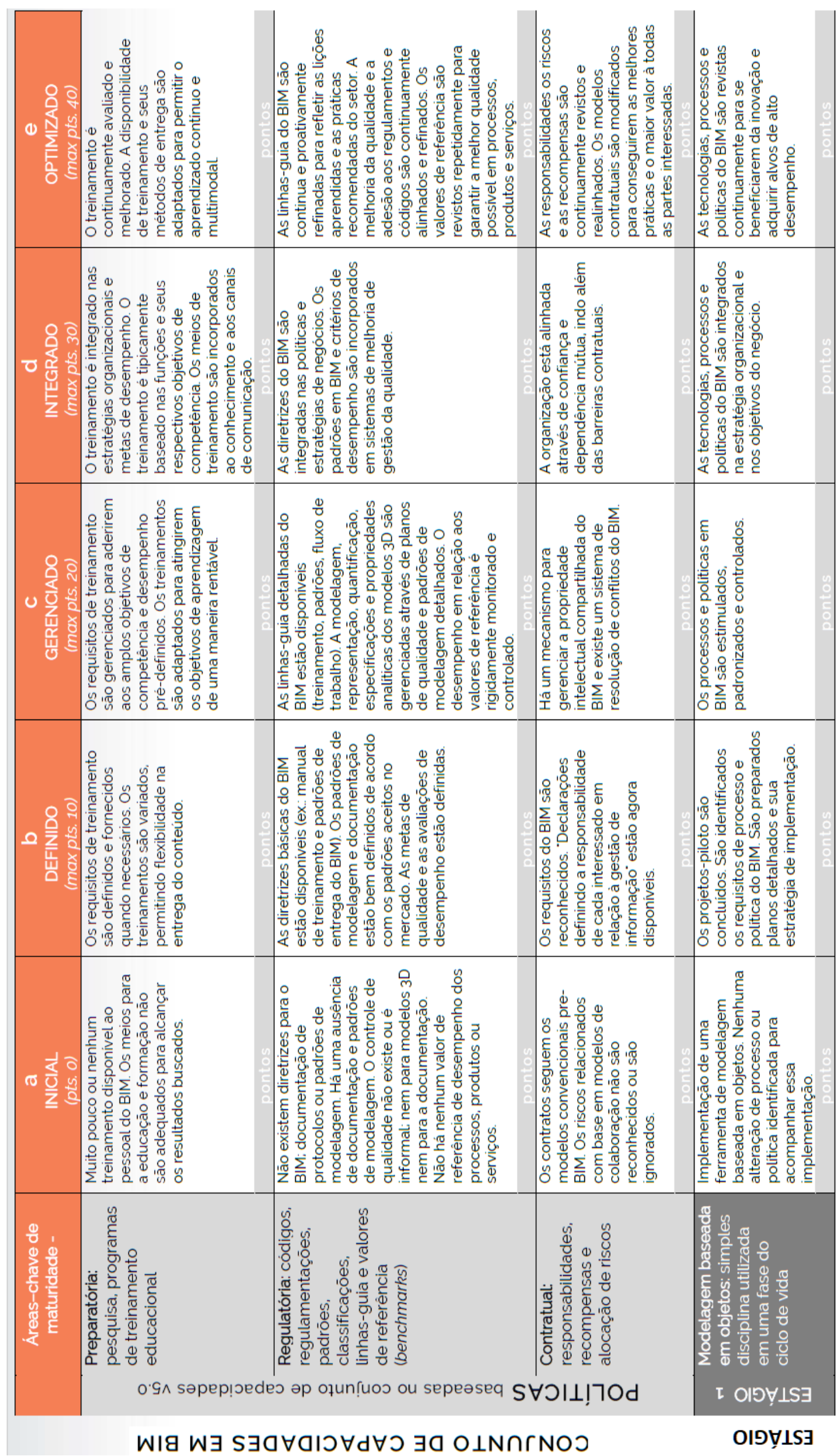


ptBIM $2020-3^{\circ}$ Congresso Português de Building Information Modelling

26 e 27 de novembro e 4 de dezembro de 2020, Faculdade de Engenharia da Universidade do Porto

\begin{tabular}{|c|c|c|c|c|c|}
\hline (1) $\frac{\mathrm{N}}{\frac{\mathrm{S}}{\mathrm{K}}}$ & 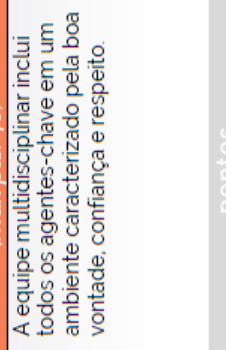 & 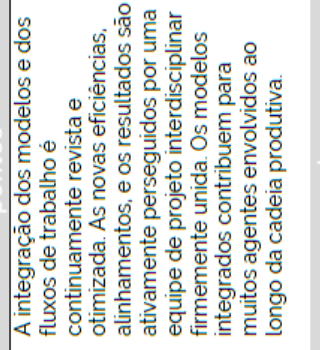 & 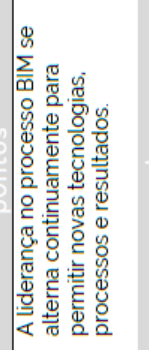 & 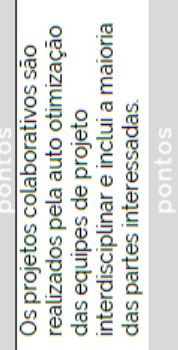 & 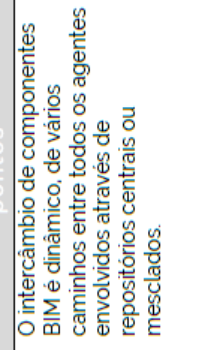 \\
\hline ర0 & 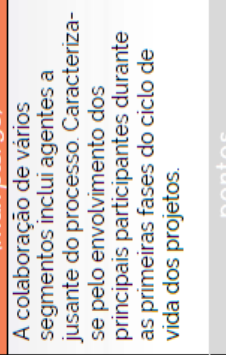 & 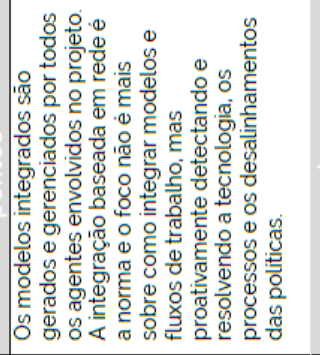 & 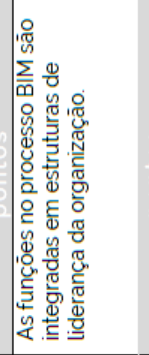 & 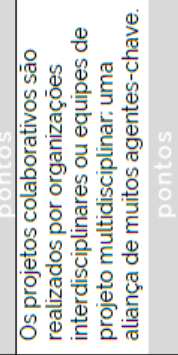 & 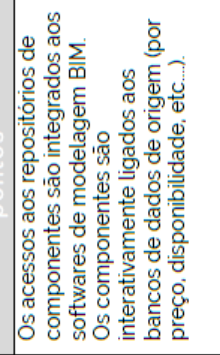 \\
\hline ن & 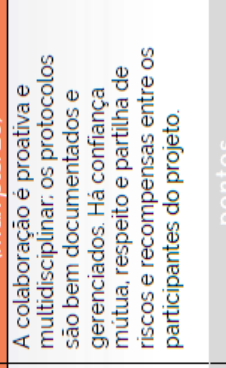 & 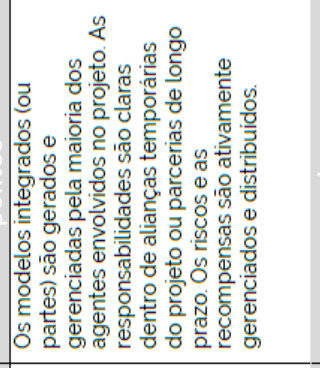 & 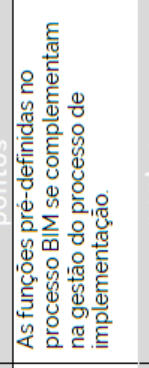 & 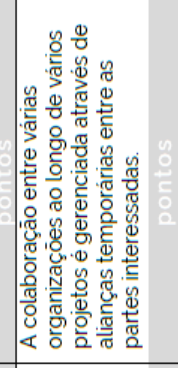 & 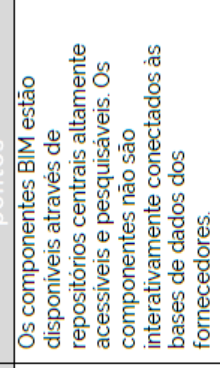 \\
\hline 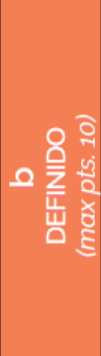 & 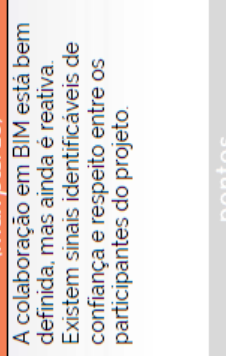 & 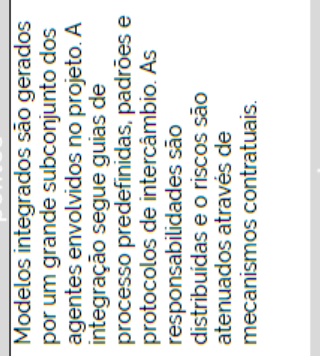 & 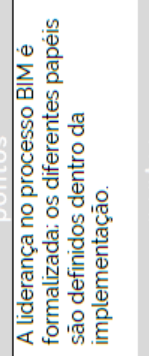 & 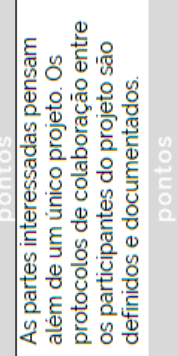 & 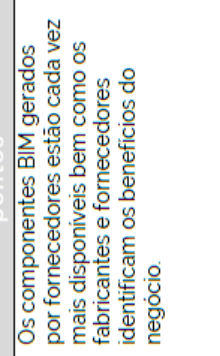 \\
\hline (1) & 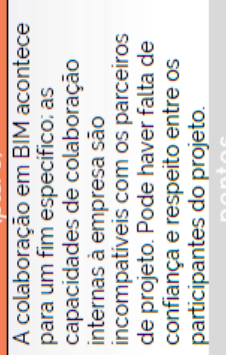 & 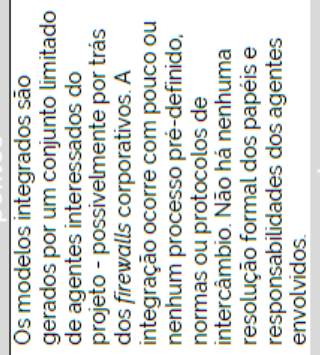 & 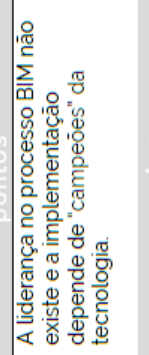 & 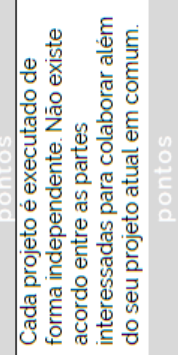 & 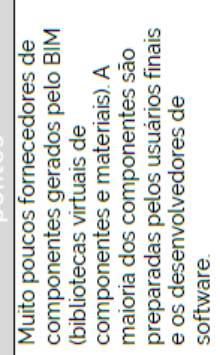 \\
\hline 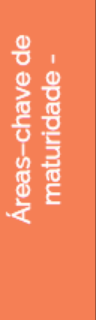 & 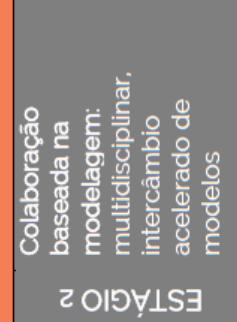 & 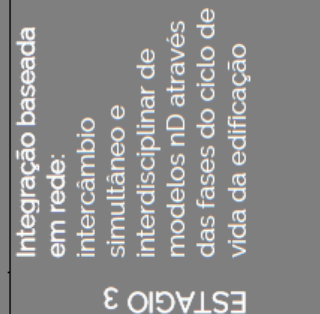 & 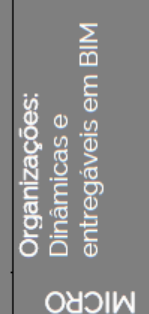 & 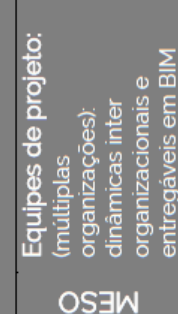 & 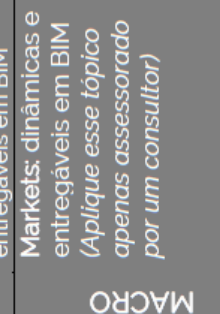 \\
\hline & & $5 \exists$ & & & \\
\hline
\end{tabular}

